\title{
Group Therapy Program for Families with Transgender Member: Propelling Gender Differentiation
}

\begin{abstract}
Eva Smidova
Nova Southeastern University, Florida, USA

This study explored impacts of a newly developed gender affirmative Group Therapy Program informed by Bowen Family Therapy approach (Bowen, 1978) for transgender individuals and their families (BFTTG). All transgender participants met criteria of gender dysphoria classified by DSM-V (DSM-V, 2014). The recent research of gender dysphoria shows that the process of transitioning is accompanied by anxiety, depression, self-mutilating, and high rate of suicide attempts (Dargie, Blair, Pukall, \& Coyle, 2014; Craig, Austin, \& McInroy, 2014; Singh \& Burnes, 2009; Levitt \& Ippolito, 2014; Mitchell, Ybarra, \& Korchmaros, 2014; Meier, Motmans, Ponnet, \& T'Sipen, 2012). Involvement and support of family in this process is crucial and it is a predictor of successful transition and life satisfaction (Ryan, Huebner, Diaz, \& Sanchez, 2010; Hill, Menvielle, Sica, \& Johnson, 2010). We have no evidence of any research regarding a structured group therapy program for this at-risk population with the whole family system (parents, guardians, youths and their siblings) involved. The Group Therapy Program (BFTTG) was predicted to be effective for these families. The program was examined on transgender individuals and their family members who were monthly attending BFTTG. The total sample consisted of 22 participants. The results showed the newly developed program helped to mobilize social support in family and related social groups. Length of participants' attendance in the group was related to decrease of anxiety in participants. Themes of the Group Program were also associated with improved level of life satisfaction perceived by participants.
\end{abstract}

Keywords: family group therapy program, gender dysphoria, transgender individuals, emotional distress, life satisfaction

The purpose of this study was to explore impacts of a newly developed gender affirmative group therapy program for transgender or gender non-conforming individuals (Bowen Family Therapy Transgender Group, hereinafter BFTTG); diagnosed with gender dysphoria classified by DSM-V as 302.85 (F64.1) Gender dysphoria in adolescents and adults and/or Gender dysphoria in children as 302.6 (F64.2) (DSM-V, 2014), and their families.

Involvement and support of a family of a non-conforming or transitioning family member is crucial and it is closely related to a life satisfaction perceived by the respective member during the process of transition and afterwards.

Eva Smidova, PhDr., M.A., TCT, Department of Marriage and Family Therapy, Nova Southeastern University; Board Member of GET (Gender-Equality-Trust) Network Foundation. Correspondence concerning this study should be sent to dr.eva.smid@gmail.com. 
The program (BFTTG) was developed based on postulates of Bowen's Family Systems Theory-Bowen therapeutic approach (Bowen, 1978) to guide families with a transgender or gender non-conforming member through the whole process of their transition and a gender challenging journey. The program targets decrease of emotional distress caused by gender dysphoria, alleviation of anxiety, and uncertainty about affordable life satisfaction.

The program was examined on family members of five respective ongoing support groups that were meeting regularly monthly since September 2014. Each group had a different format. There was BFTTG for trans teens, BFTTG for trans children, BFTTG for parents and allies, BFTTG for trans adults, and BFTTG mixed group for anyone-whole families, or any individual family member. The total sample consisted of 22 participants.

From the perspective of Bowen Family Systems Theory, family represents a unit (Bowen, 1978). In that respect, gender transition of a family member requires transition of the family system equally. The BFTTG approach involves work with the entire family system (parents, guardians, youths and their siblings), exploration of identity and identity shaping, self-differentiation, targeted decrease of anxiety via progressing transition on a scale of self-differentiation towards individuation, yet obtaining and accepting support of family towards togetherness - experience of belonging (Bowen \& Kerr, 1988).

The recent research of gender dysphoria shows that insecure gender identity in the process of transitioning, including the phase of questioning one's birth-assigned gender, is almost always accompanied by some kind of an emotional distress such as anxiety, depression, uncertainty about members' future and life, post-traumatic stress, substance abuse, self-mutilating, and high rate of suicide attempts. The transgender and gender non-conforming population belongs to "at-risk population” (Bostwick et al., 2010; Dargie et al., 2014; Craig et al., 2014; Singh \& Burnes, 2009; Levitt \& Ippolito, 2014; Mitchell et al., 2014; Meier et al., 2012; Zucker, Wood, Singh, \& Bradley, 2012; Rothblum et al., 2013; Mathy, 2002; Pitts, Couch, Mulcare, Croy, \& Mitchell, 2009). Standards of Care for the Health of Transsexual, Transgender, and Gender-Nonconforming People (herein after referred as SOC) mention also a higher prevalence of autism spectrum disorders in this population (Coleman et al., 2011).

\section{Gender Dysphoria and the Role of Family Support}

Involvement and support of family in the treatment-psychotherapy of gender dysphoria is crucial and it is a predictor of successful transition and life satisfaction. The lack of family involvement and support over the transitioning process belongs to the most reported reasons of psychological distress by the transgender population (Fausto-Sterling, 2012; Vries \& Cohen-Kettenis, 2012; Ryan et al., 2010; Hill, Menvielle, Sica, \& Johnson, 2010). Despite its importance, the significant role and a possible positive impact of family involvement is not adequately reflected in treatment approaches that are mostly individual—gender dysphoria diagnosed and client-centered. SOC include family or group psychotherapy as a treatment option, besides individual medical treatment, either hormonal or surgical (Coleman et al., 2011). SOC guidelines of care also list family support as a possible psychological and social intervention for children and adolescents. SOC report that self-exploration, understanding, recognition, self-acceptance, self-efficacy, affirmative approach to self-identity belong among the core competencies and targeted approaches when working with transgender and gender non-conforming clients (Coleman et al., 2011). The American Association for Lesbian, Gay, Bisexual, 
and Transgender Issues in Counseling (ALGBTIC) refers only to an individual care with the respective clients in Competencies for Counseling with Transgender Clients (Burnes et al., 2003).

\section{Bowen Therapeutic Approach Paradigm for Group Therapy with Transgender and Gender Non-Conforming Families}

Bowen Family Systems Theory therapeutic perspective approaches individuals as an undividable part of a family system. Every human being enters the world dependent on others for their well-being (Bowen, 1978).

Family represents an emotional unit. The emotional unit provides a basic foundation of any family system. Emotional system represents a general survival drive common to all living species, as well as unique survival patterns, strategies, and know-hows of the respective, particular family system that are transmitted from generation to generation (Bowen, 1978).

Differentiation of self is a continuing process of encountering of two core life forces: togetherness-the need to belong to a family, and individuality - the ability to act and take decisions independently and confidently alone. Functional level of self-differentiation relates to a management of everyday situations and challenges. Individuals with higher level of self-differentiation experience less anxiety and are less emotionally reactive. Higher level of self-differentiation and lower level of anxiety is not possible to reach through turning away from the respective family but in relation to the family. Well self-differentiated individuals are capable to direct their life and solve problems, to be self-sustaining and living independently and successfully (Bowen \& Kerr, 1988).

Transgender and gender-questioning individuals face self-differentiation from their assigned gender to their expressed, authentic gender. This process of gender differentiation is accompanied by a significant level of emotional distress. Well gender differentiated individuals are capable to use potential of the assigned gender and benefit from it in their expressed gender with low level of anxiety and dysphoria. Successful gender differentiation and well-being is determined by getting support from their family, significant others, or any related social group.

A Bowen therapy informed approach applied in group therapy with family of transgender and gender-questioning population features participation of the nuclear family system (identified transgender or gender-questioning individual, their parents or legal guardians, and possible sibling/s). The program intends to decrease anxiety in the family system and in the individual. Lower level of anxiety allows improvement of a functional level of self-differentiation of individuals, and prompts ability to focus on identifying and holding on own personal values, and goals. Participants are guided to take control over their emotional processes with help from their families as a form of building resilience through the transitioning process. BFTTG searches for gender models in family as a way of recognition and self-identity acceptance, and use of self-differentiation from at birth assigned gender identity (based on a biological sex) as a benefit and condition for success in the expressed gender identity. The program also features psycho-education and coaching through the transitioning process.

The purpose of the study was to examine whether the newly developed program helped to mobilize social support in family and related social groups (allies) and if the involved family members and the length of attendance influenced participants' level of anxiety. The study also brings an overview of group topics assessed by participants that are related to their experience of life satisfaction and the most frequent group topics preferred by participants. 


\section{Literature Review}

\section{Gender Identity Development and Family Support}

Recent research in this area approaches transgender and gender-questioning individuals as at-risk population and examines way how to increase their resilience, provide them with support, resources, and strategies for dealing with social pressure (real or anticipated) and fear from stigma (Minter, 2012).

Researchers from the department of Biology and Gender Studies of the Brown University, Providence, developed a dynamic systems framework for gender identity development and stressed a significant impact of parent-child relationship on gender identity development. Gender identity and gender-related behaviors emerge as a pattern of several cooperating parts—a child finds the experience of self within a relationship in which he or she is already seen. The internalization of the gender/body mirror becomes a part of the child's procedural knowing (Fausto-Sterling, 2012).

The Dutch Approach study determined comprehensive assessment of gender dysphoria by a good assessment of family functioning and the role of the youth's gender variant behavior on family functioning (Vries \& Cohen-Kettenis, 2012). Researchers assume that building of secure and positive self-image can be obtained via developing a rapport with adolescents and their parents, particular via obtaining open and nonjudgmental contact with the youths and their parents (Vries \& Cohen-Kettenis, 2012). Researches at the Family Acceptance Project at San Francisco State's Marian Wright Edelman Institute for the Study of Children, Youth, and Families examined that gender nonconforming individuals who receive support from their families for their sexual or gender identities show better mental health functioning than their peers who do not (Ryan et al., 2010; Hill, Menvielle, Sica, \& Johnson, 2010). Another research study conducted by Ryan and colleagues (Ryan, Russell, Huebner, Diaz, \& Sanchez, 2010) showed the compelling relationship between family acceptance of transgender individuals and significantly higher level of self- esteem, social support, and general health in adulthood (Ryan et al., 2010). Also family support towards the youth's gender expression belongs to the most significant protective factors and predictors of their life satisfaction (Ryan et al., 2010). Canadian research study of suicide risk in transgender community found high social support, specifically parental support, is the potential prevention of consideration of suicide (Bauer, Deutsch, Massarella, \& Scheim, 2014).

Therapeutic approaches towards transgender and gender-questioning clients. Stein (2012) suggests that the only appropriate interventions for individuals who experience distress about their gender at the phase of questioning their gender and exploring their gender identity, are to provide counseling to the whole family (Stein, 2012). Dianne Ehrensaft, child clinician from the Department of Pediatrics, University of California San Francisco, developed a creative individual clinical approach called "True gender self therapy (TGST)" (Ehrensaft, 2012). The goal of the therapy is to help the clients to establish gender resilience and explore authentic gender identity, yet acknowledge possible social limits, constraints that the clients have to be aware of. She also recommends participation in support groups for the youths and separate support groups for parents (Ehrensaft, 2012). Affirmative therapy adopts a positive view of transgender clients by respecting their self-defined identities (Benson, 2013). Interviews conducted with seven transgender individuals revealed these expected outcomes of effective therapy: improvement of quality of life that refers to well-being, relationship satisfaction, and emotional health. Participants considered affirmation of identity as an essential part of the effective therapeutic help (Benson, 2013). Researchers from the Department of Psychiatry and Behavioral 
Sciences, Children's National Medical Center, Washington, introduced a clinical program designed for transgender families (Menvielle, 2012). Although the program is separating parental and youths group, it belongs to one out of very few clinical programs designed for transgender families in this field (Menvielle, 2012). Resiliency in the trans individuals is best achieved through a supportive family environment that fosters the development of self-esteem and social competences (Wyman, Sandler, \& Nelson, 2000). Team of Canadian clinicians from the Gender Identity Service at the Centre for Addiction and Mental Health in Toronto introduced a therapeutic model that supports trans individuals in adapting to whatever stressors may be associated with their gender identity, improves experience of their well-being, and leads parents to help their children with adaptation to various developmental tasks (Zucker et al., 2012). An Interdisciplinary Clinic for Youths with gender dysphoria, under the Pediatric Center in Harvard Medical School, Boston, approaches "homophobia and transphobia" among family members and related social environment with a collaborative strategy (Edwards-Leeper \& Spack, 2012). Team of researchers from the University Toronto and the Barry University found out that social connectedness has been identified as a significant predictor of well-being for the trans population (Detrie \& Lease, 2008), and has been found to positively influence self-esteem and decrease anxiety and depression (Kohut, 1984; Lee \& Robbins, 1998). Sharing authentic experiences of participants in group is supposed to have a powerful impact on decreasing sense of isolation of participants during a potentially stressful period of gender identity development (Craig et al., 2014). Michael Rogers from the University of California, in Santa Barbara, was mapping specialized LGBTQ community based programs focused on an improvement of emotional health and life satisfaction of the targeted population (Rogers, 2012). The effect and beneficial impact of the program is in a community involvement and support (Rogers, 2012).

Life satisfaction. The general goal of psychotherapy with transgender and gender-questioning families according to SOC is to help to maximize client's psychological well-being, quality of life and reach comfortable level of life satisfaction (Coleman et al., 2011).

Expression of life satisfaction is very individual as well as its experience for each person in the targeted group (Phelps et al., 2012). Research of everyday life satisfaction of ethnic minority groups found the significance of the experience of feeling of adaptation and belonging to the major population (Verkuyten, 2008). Scientists bring evidence of three significant factors of life satisfaction: psychological distress, social support, and spirituality (Phelps et al., 2012). Emerging research of transgender population confirms that involvement and support of family is a predictor of successful transition and life satisfaction (Ryan et al., 2010; Hill et al., 2010; Fausto-Sterling, 2012; Vries \& Cohen-Kettenis, 2012).

\section{Method}

\section{Sample}

The current sample was comprised of 22 trans or gender-questioning individuals (age 7-68; average age of participants 36.47) and their close family members. Of the 22 participants in the BFTTG group, there were 14 trans individuals and 8 family members. Nine trans individuals represented males to females (MtF), and five females to males (FtM). All participants were attending BFTTG groups for 1 month to more than 1 year. The most common racial demographic was Caucasian (94.5\%) and 4.5\% was Hispanic. 91\% of all participants had some evidence of mental health issues in the family history, specifically depression, anxiety, panic attack, 
suicidal ideation or suicidal attempt. 59\% of trans individuals had their family involved and supportive either directly or indirectly, whereas $41 \%$ (all of them trans adults) did not have family involved and supportive. Of 22 trans individuals, there were $21 \%$ trans heterosexuals, and $79 \%$ homo or bisexuals. $27 \%$ of participants reported history of LGBTQ member in the close or extended family. 59\% of participants were high school graduates, $9 \%$ college graduates.

Data were collected via nonprobability sampling—not a random selection—and might not be a representative of the population. Participants represent a convenient sample consisting of trans and gender-questioning individuals, and their family members who were attending BFTTG support groups between September 2014 and May 2016.

Group participants accepted to the family transgender support group were all individuals who reported significant discomfort concerning their gender and their close family members. Exclusion criteria was English proficiency or refusal to sign an informed consent declaration.

\section{Procedures}

All participants who were attending transgender support groups (about 100 individuals) with GET Network Foundation, non-profit organization, were informed about an offer to participate in the research. All group members obtained two questionnaires: The Beck Anxiety Inventory (BAI), for this research developed questionnaire the Gains from BFTTG Program, and a brief demographic inventory. All participants signed an informed consent and filled out anonymously the above stated forms.

Besides the participants, group leaders were asked to monitor the most frequent topics brought by all groups participants over one year. All group leaders filled out 10-point Likert scale instrument "The Group Topics Scale" that was designed for the purpose of this study.

\section{Measures}

A paper-and-pencil brief Demographic questionnaire, developed for this study, contains 10 items and it assesses assigned gender, expressed gender, family involved, race, education, sexual orientation, history of mental health issues in a family, LGBTQ individual in close or extended family, religion, education.

The Beck Anxiety Inventory (BAI) (Beck \& Steer, 1993), a paper-and-pencil self-report questionnaire assesses in 21 4-point Likert scale items the severity of anxiety in the youth and adults. The BAI maximum score of the summed points is 63 . Score of 41-63 is considered for a severe anxiety, 26-40 for a significant anxiety, 15-25 moderate anxiety, under 15 low level of anxiety — healthy. Evaluation of reliability and validity of the Beck Anxiety Inventory the BAI proved highly internally consistent-Cronbach's alpha $=0.94$ (Fydrich, Dowdall, \& Chambless, 1992).

The Gains from the BFTTG Program questionnaire was developed for this research as a self-report paper-and-pencil questionnaire to assess expectations of participants from the BFTTG program. The Gains from the BFTTG Program were interpreted to participants as their personal expectations and their perception that represent their individual experience of well-being and life satisfaction. This instrument consists of 17 5-point Likert scale items on which participants express to what extent they consider listed gains significant for them. Likert scale is anchored as 5 = "Significantly important"; 4 = "Somewhat important"; $3=$ "Neutral"; 2 = "A bit important”; 1 = "Not important”. Among the possible gains there are listed items such as unconditional acceptance, support of expressed gender, handling stress, dealing with family relationships, help from the group and group members, psycho-education. 
The collected data were quantitatively assessed. Descriptive statistics (frequency distribution, central tendency, dispersion) was used to describe demographic structure of participants (Figure 1), to depict frequency of topics in all five groups over one year (Table 2), central tendency was used to measure gains from the group program related to the participant's well-being and life satisfaction (Figure 2), and to show an average level of anxiety, average level of anxiety of participants attending the BFTTG less than 1 year, and those attending the program more than 1 year (Figure 3). Then, correlations were used to assess relation between attendance (from 1 month to more than 1 year) in the group (independent variable) and level of participants' anxiety (dependent variable) (Table 1).

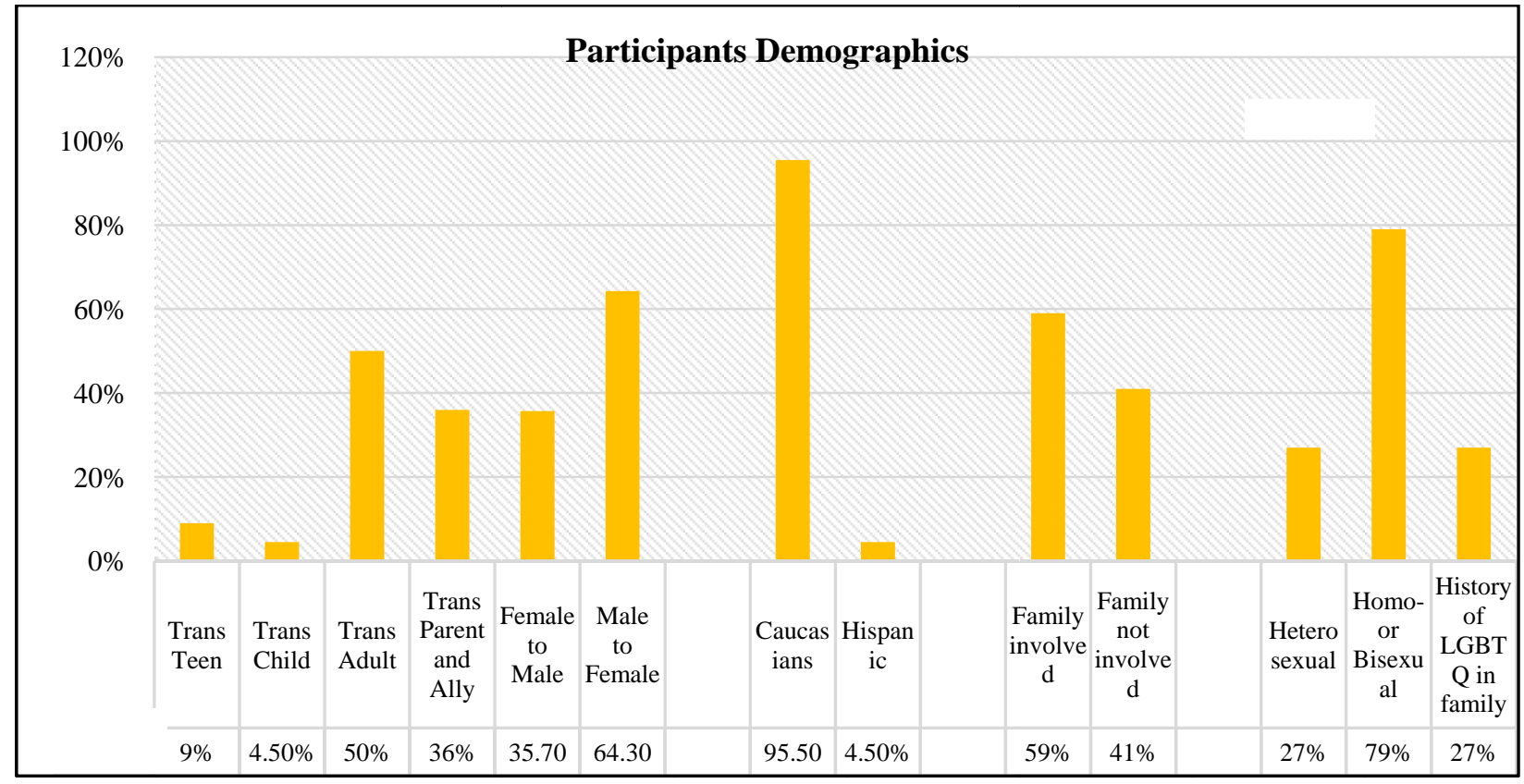

Figure 1. Demographics. History of LGBTQ in Family refers to any close or extended family member/s who expressed or expresses himself/herself either as transgender, gender non-conforming, homosexual, bisexual, etc.

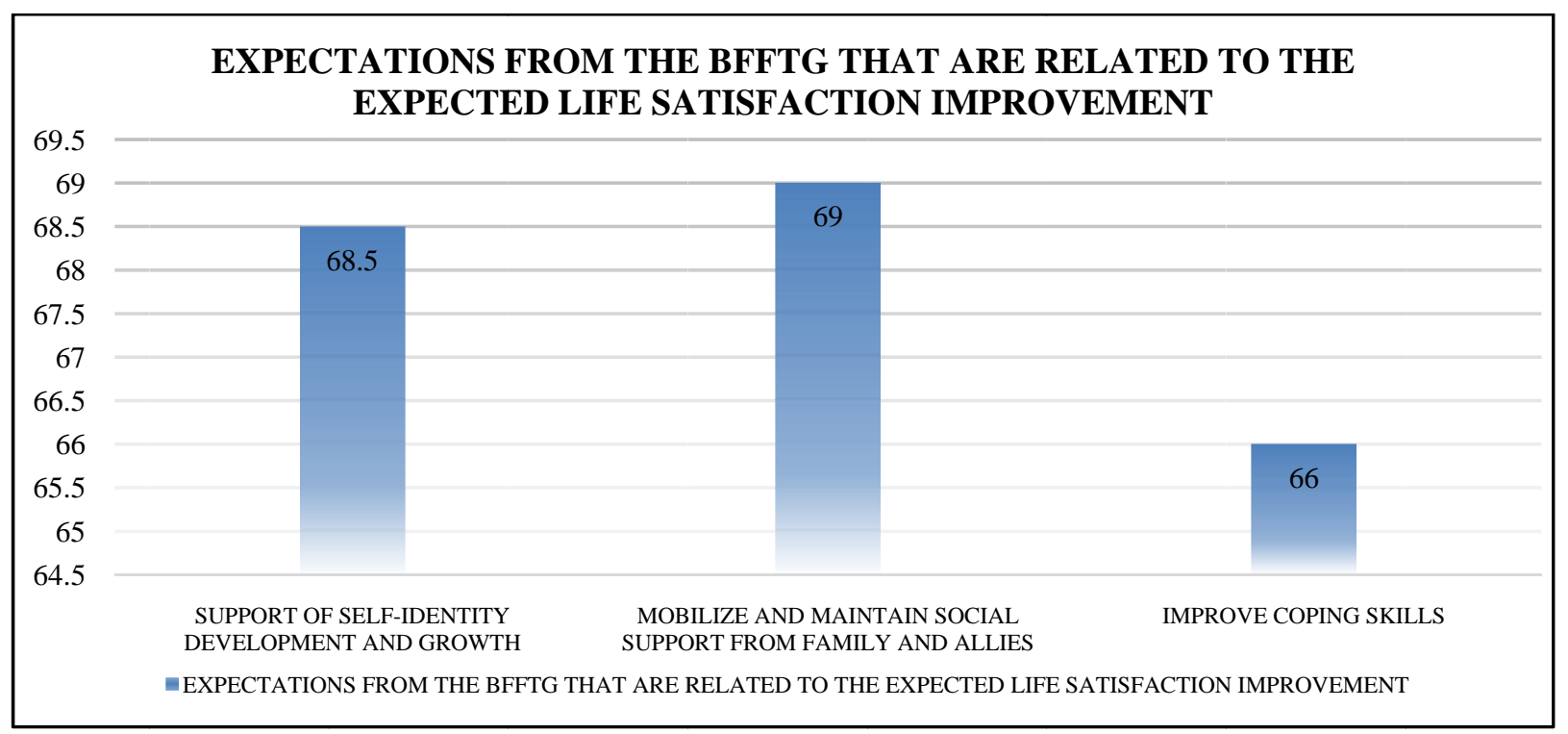

Figure 2. Gains from the group program related to the participant's well-being and life satisfaction. 


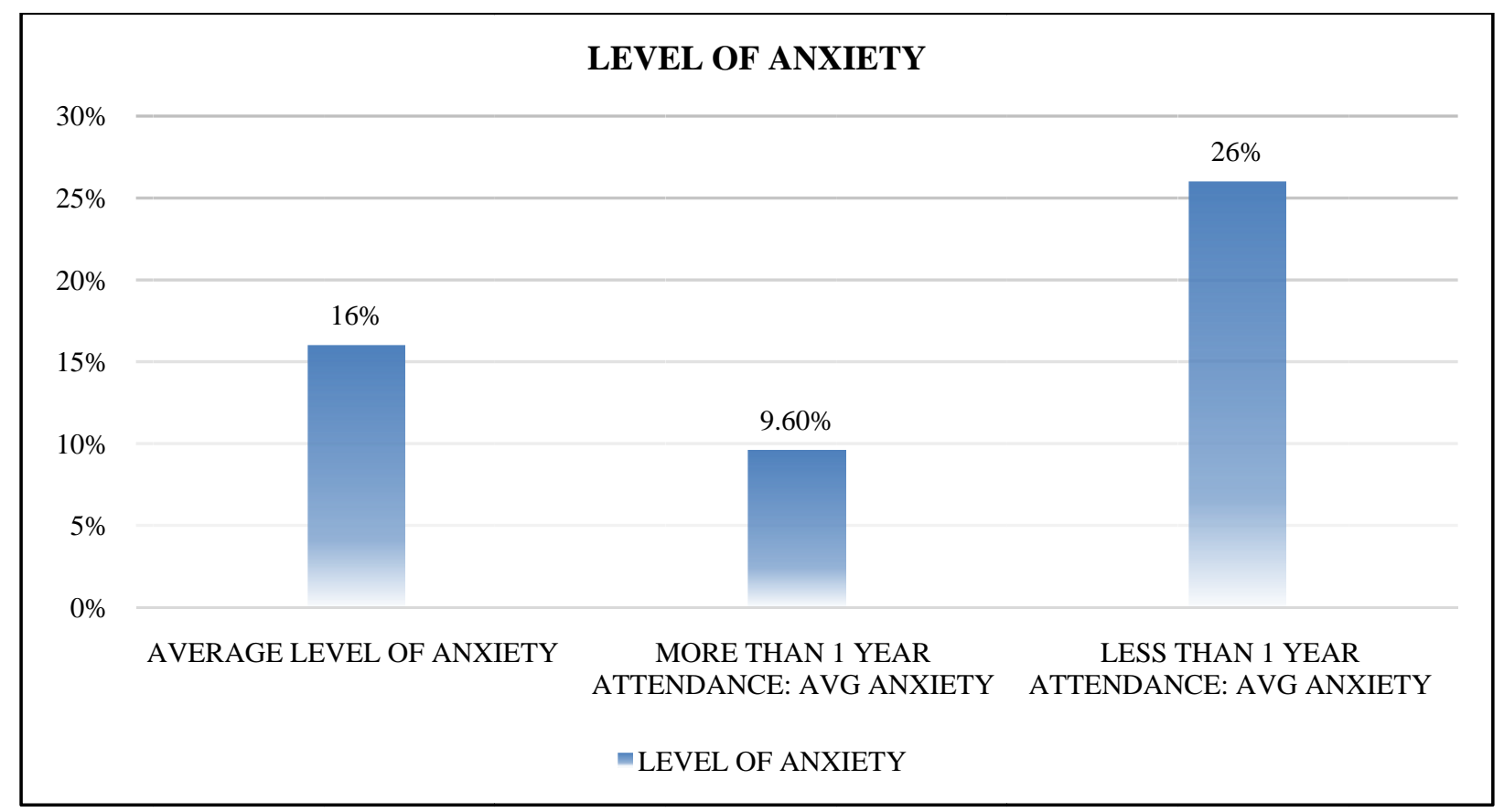

Figure 3. Level of anxiety in participants.

Table 1

Correlation of Attendance in the Group and Level of Participants' Anxiety $(N=19)$

\begin{tabular}{lllc}
\hline & & Length of attendance in BFTTG & Level of anxiety measured by BAI \\
\hline \multirow{2}{*}{$\begin{array}{lll}\text { Length of attendance in } \\
\text { BFTTG }\end{array}$} & Pearson Correlation & 1 & -0.353 \\
& Sig. (2-tailed) & & 0.138 \\
\hline \multirow{2}{*}{$\begin{array}{l}\text { Level of anxiety measured } \\
\text { by BAI }\end{array}$} & $N$ & 19 & 19 \\
& Pearson Correlation & -0.353 & 1 \\
& Sig. (2-tailed) & 0.138 & 19 \\
\hline
\end{tabular}

Notes. The level of anxiety (dependent variable) was assessed on Likert Scale 0-3, with 3 = "Strong"; 2 = "Moderate"; 1 = "Weak"; 0 = "Nothing"; The gains from the BFTTG program (independent variable) were assessed on Likert Scale of 1-5, with 5 = "Significantly important”; 4 = "Somewhat important”; 3 = "Neutral”; 2 = "A bit important”; 1 = "Not important".

Table 2

Frequency of Group Topics Across Transgender Support Groups $(N=5)$

\begin{tabular}{|c|c|c|c|c|c|c|c|c|c|c|c|c|}
\hline & $\begin{array}{l}\text { Trans } \\
\text { Gender } \\
\text { Support } \\
\text { Group }\end{array}$ & $\begin{array}{l}\text { Sexualit } \\
\text { y/ dating }\end{array}$ & $\begin{array}{l}\text { Express } \\
\text { ed/ } \\
\text { assigned } \\
\text { identity }\end{array}$ & $\begin{array}{l}\text { Treatme } \\
\text { nt issues }\end{array}$ & $\begin{array}{l}\text { Grievin } \\
\text { g, loss }\end{array}$ & $\begin{array}{l}\text { Family } \\
\text { and } \\
\text { relationa } \\
\text { l issues }\end{array}$ & $\begin{array}{l}\text { My life } \\
\text { as a } \\
\text { trans- } \\
\text { daily } \\
\text { issues }\end{array}$ & $\begin{array}{l}\text { My life } \\
\text { as a } \\
\text { trans at } \\
\text { work, at } \\
\text { school, } \\
\text { etc. }\end{array}$ & $\begin{array}{l}\text { Bullying } \\
\text { /Mobbin } \\
\text { g/Oppre } \\
\text { ssion of } \\
\text { my } \\
\text { rights }\end{array}$ & $\begin{array}{l}\text { Coping } \\
\text { skills }\end{array}$ & $\begin{array}{l}\text { Coming } \\
\text { out }\end{array}$ & Others ${ }^{*}$ \\
\hline \multirow[t]{2}{*}{$N$} & 5 & 5 & 5 & 5 & 5 & 5 & 5 & 5 & 5 & 5 & 5 & 5 \\
\hline & 0 & 0 & 0 & 0 & 0 & 0 & 0 & 0 & 0 & 0 & 0 & 0 \\
\hline Mean & 3 & 4.4 & 9 & 4.4 & 3.6 & 9.6 & 7.6 & 9 & 7.2 & 8 & 7.6 & 8.2 \\
\hline $\begin{array}{l}\text { Std. Error of } \\
\text { Mean }\end{array}$ & 0.707 & 1.364 & 0.632 & 1.47 & 1.691 & 0.245 & 0.678 & 0.632 & 0.663 & 0.894 & 0.245 & 0.917 \\
\hline Median & 3 & 5 & 10 & 6 & 4 & 10 & 8 & 10 & 7 & 9 & 8 & 8 \\
\hline Std. Deviation & 1.581 & 3.05 & 1.414 & 3.286 & 3.782 & 0.548 & 1.517 & 1.414 & 1.483 & 2 & 0.548 & 2.049 \\
\hline Variance & 2.5 & 9.3 & 2 & 10.8 & 14.3 & 0.3 & 2.3 & 2 & 2.2 & 4 & 0.3 & 4.2 \\
\hline
\end{tabular}


Table 2 to be continued

\begin{tabular}{lllllllllllll}
\hline Skewness & 0 & -0.543 & -0.884 & -0.518 & 0.516 & -0.609 & -0.315 & -0.884 & -0.552 & -0.938 & -0.609 & -1.022 \\
$\begin{array}{l}\text { Std. Error of } \\
\text { Skewness }\end{array}$ & 0.913 & 0.913 & 0.913 & 0.913 & 0.913 & 0.913 & 0.913 & 0.913 & 0.913 & 0.913 & 0.913 & 0.913 \\
Kurtosis & -1.2 & -0.003 & -1.75 & -1.687 & -0.725 & -3.333 & -3.081 & -1.75 & 0.868 & -0.188 & -3.333 & 0.918 \\
Std. Error of & 2 & 2 & 2 & 2 & 2 & 2 & 2 & 2 & 2 & 2 & 2 & 2 \\
Kurtosis & 4 & 8 & 3 & 8 & 9 & 1 & 3 & 3 & 4 & 5 & 1 & 5 \\
Range & 4 & 0 & 7 & 0 & 0 & 9 & 6 & 7 & 5 & 5 & 7 & 5 \\
Minimum & 1 & 8 & 10 & 8 & 9 & 10 & 9 & 10 & 9 & 10 & 8 & 10 \\
Maximum & 5 & 8 &
\end{tabular}

Notes. " Others: Legal Issues, References, Friends’ Acceptance; The frequency of group topics was monitored and assessed by group leaders on Likert Scale from 1-10, where 1 is the least frequent and 10 is the most frequent agenda in the support groups. The three most frequent topics across the groups were: Expressed Identity/Assigned Identity; Family and Relational Issues; My Life as a Transgender Individual at Work, School, etc. All three topics are related to being socially accepted (how to pass and get support in a microsystem-family and allies, and in a mesosystem-related social groups). All three topics are significantly related to reported gains from transgender support group program. The accomplishment of the goals/gains expected from the groups refers to a quality of life of trans community.

\section{Results}

The three most frequent topics across all five groups were Family and Relational Issues $(M=9.60, S D$ 0.548), Expressed Identity/Assigned Identity $(M=9.00, S D=1.414)$, and My Life as a Transgender Individual at Work, School, etc. $(M=9.00, S D=1.414)$.

Gains from the BFTTG program related to the participant's well-being and life satisfaction with the highest frequency were "Mobilize and Maintain Social Support from Family and Allies" (69\% of participants), "Support of Self-identity Development and Growth" (68.5\% of participants), and "Improvement of Coping Skills" (66\% of participants). Other significantly less charged outcomes (between $40 \%-50 \%$ participants chose them) were psycho-education, health care, social status, and employment.

The average level of anxiety by all participants was $16.0 \mathrm{BAI}$ points $(M=16.05, S D=13.962)$ that refers to moderate anxiety (Beck \& Steer, 1993). The highest level of measured anxiety was 50.0 BAI and the lowest level of measured anxiety was as low as 1.0 BAI points. Participants who were attending BFTTG program for more than 1 year had an average level of anxiety 9.6 BAI points that refers to low level of anxiety (Beck \& Steer, 1993). Participants attending BFTTG program for less than 1 year had an average level of anxiety 26.0 BAI that refers to significant level of anxiety (Beck \& Steer, 1993).

Correlation was used to examine if there is any relationship between the length of attendance of the BFTTG program and level of anxiety in participants. The mean time of attendance was 7.63 months $(S D=$ 5.145). The shortest time was 1 month and the longest time was over one year. The correlation coefficient was $r(19)=-0.353, p<0.05$. The results suggest a negative correlation with moderate magnitude between the attendance and anxiety.

\section{Discussion}

Support groups for transgender and gender-questioning individuals are usually unstructured groups without any particular agenda or program. The general aim is to provide social support. A newly developed program is focused on mobilization of social support in family and related social groups (allies). BFTTG is informed by Bowen Family Systems Theory therapeutic approach and aims to decrease an emotional distress 
related to gender dysphoria, alleviate anxiety, depression, and uncertainty about member's life and future via progressing transition with having a respective family system involved. From the perspective of the Bowen Family Systems Theory, gender transition of a family member requires transition of the family system equally.

In compliance with the Bowen Systems Theory, the format of the group was a family. Opening the group to all family members allowed them to be involved either directly as participants of the group or indirectly as supporting the particular participant in the group (bringing him/her to the group, sharing, communicating with other families of participants). Family group aimed to mobilize family support as a context that provides a basic foundation in the process of a self-differentiation of the transgender and gender-questioning member. Functional self-differentiation of the transgender and gender-questioning member is possible when level of anxiety in the family system and in the individual is low. Participants were guided to take control over their emotional processes with help from their families as a form of building resilience through the transitioning process. BFTTG searched for gender models in family as a way of recognition and self-identity acceptance. BFTTG used self-differentiation from at birth assigned gender identity (based on a biological sex) as a benefit and condition that navigated participants successfully to the expressed gender identity.

Participants were asked at the beginning of the BFTTG about their expectations, gains from BFTTG that would help them to improve their perceptions of their individual life satisfaction. Group leaders then monitored frequency of the topics discussed as the preferred, important, and required by participants in the groups.

The program was structured as flexible so it could accommodate all family members. The topics were broad and group leaders approached the topics from the developmental perspective of the targeted support group of participants. The total sample consisted of 22 participants who attended BFTTG support group for a period of one month through one year.

This research study examined two factors: participation and/or involvement of the entire family system in the newly developed BFTTG program for transgender/gender-questioning individuals and their families and its effect on their level of anxiety, as well as its relation if any, to their well-being and experience of life satisfaction.

The results indicate that more than half of participants 59\% had family involved in the BFTTG program. The BFTTG program structured for the entire family system helped to mobilize attendance or either emotional or instructional support of families of transgender and gender-questioning individuals. Participants without family support belonged mostly to participants in age category $50+$.

The univariate analysis shows that participants who were attending BFTTG program for more than 1 year had an average level of anxiety significantly lower than participants attending BFTTG program for less than 1 year. Also the correlation of relationship between the length of attendance of the BFTTG program and level of anxiety in participants showed an association between decreasing anxiety with increasing attendance in BFTTG program.

The three most frequent topics across the groups were: Expressed Identity/Assigned Identity; Family and Relational Issues; My Life as a Transgender Individual at Work, School, etc. The three most frequent topics in all groups are related to a need of being socially accepted (how to pass socially, how to get support and acceptance in the microsystem of a family, and in related social groups). All three topics are also related to reported gains from the BFTTG program that reflect participants' well-being and life satisfaction-mobilize and maintain social support from family and allies, support of self-identity development and growth, and improvement of coping skills as a condition of social acceptance. 
The implications of research results might be beneficial for this unique at-risk population. BFTTG program has a potential to be effectively used for treatment of gender dysphoria and psychological distress related to this diagnosis. The implications might positively influence life satisfaction and mental health of the targeted population.

\section{Limits and Ethical Issues}

All participants signed the informed consent regarding the research study. The number of participants was small and it represented a non-probability sample. We took into consideration other variables that potentially might influence research results among them at birth assigned gender and expressed gender (female to male, male to female); age; history of mental health issues in family; and intensity and duration of family support. We used correlation to assess relationship between gender, age, and level of anxiety but the correlation was not significant.

\section{References}

American Psychiatric Association. (2014). Diagnostic and statistical manual of mental disorders (5th ed., text revision). Washington, DC: Author.

Bauer, G. R., Deutsch, M. B., Massarella, C., \& Scheim, A. I. (2014). Reported emergency department avoidance, use, and experiences of transgender persons in Ontario, Canada: Results from a respondent-driven sampling survey. Annals of Emergency Medicine, 63(6), 713-720.e1. doi:10.1016/j.annemergmed.2013.09.027

Beck, A. T., \& Steer, R. A. (1993). Beck Anxiety Inventory Manual. San Antonio, TX: Psychological Corporation.

Bostwick, W. B., Boyd, C. J., Hughes, T. L., \& McCabe, S. E. (2010). Dimensions of sexual orientation and the prevalence of mood and anxiety disorders in the United States. American Journal of Public Health, 100(3), 468-475.

Bowen, M. (1976). Theory in the practice of psychotherapy. In P. J. Guerin, Jr. (Ed.), Family therapy: Theory and practice (pp. 42-90). New York, NY: Garner Press.

Bowen, M. (1978). Family therapy in clinical practice. Northvale, NJ: Jason Aronson Inc.

Bowen, M., \& Kerr, M. E. (1988). Family evaluation: An approach based on Bowen Theory. New York, N.Y.: W. W. Norton \& Company.

Burnes, T. R., et al. (2003). Association for lesbian, gay, bisexual, and transgender issues in counseling (ALGBTIC): Competencies for counseling with transgender clients. Retrieved from: http://www.algbtic.org/resources/competencies.html

Cohen-Kettenis, P. T., Owen, A., Kaijser, V. G., Bradley, S. J., \& Zucker, K. J. (2003). Demographic characteristics, social competence, and behavior problems in children with gender identity disorder: a cross-national, cross-clinic comparative analysis. Journal of Abnormal Child Psychology, 31, 41-53.

Coleman, E. et al. (2011). Standards of care for the health of transsexual, transgender, and gender-Nonconforming People version 7.0: Differentiation of Self Inventory. International Journal of Transgenderism, 13, 165-232, doi:10.1080/ 15532739.2011.700873

Craig, S. L., Austin, A., \& McInroy, L. B. (2014). School-based groups to support multiethnic sexual minority youth resiliency: Preliminary effectiveness. Child Adolescence Social Work Journal, 31(87), 87-106, doi:10.1007/s10560-013-0311-7

Dargie, E., Blair, K. L., Pukall, C. F., \& Coyle, S. M. (2014). Somewhere under the Rainbow: Exploring the identities and experiences of trans persons. The Canadian Journal of Human Sexuality, 23(2), 60-74.

Detrie, P. M., \& Lease, S. H. (2008). The relation of social support, connectedness, and collective self-esteem to the psychological well-being of lesbian, gay, and bisexual youth. Journal of Homosexuality, 53(4), 173.

Drescher, J., \& Byne, W. (2012). Gender Dysphoric/Gender Variant (GD/GV) children and adolescents: Summarizing what we know and what we have yet to learn. Journal of Homosexuality, 59(3), 501-510, doi:10.1080/00918369.2012.653317

Edwards-Leeper, L., \& Spack, N. P. (2012). Psychological evaluation and medical treatment of transgender youth in an interdisciplinary gender management service (GeMS) in a major pediatric center. Journal of Homosexuality, 59(3), 321-336, doi:10.1080/ 00918369.2012.653302

Egbochuku, E. O., \& Aihie, N. O. (2009). Peer group counseling and school influence on adolescents' self-concept. Journal of Instructional Psychology, 36(1), 3-12. 
Ehrensaft, D. (2012). From gender identity disorder to gender identity creativity: True gender self child therapy. Journal of Homosexuality, 59(3), 337-356, doi:10.1080/00918369

Fausto-Sterling, A. (2012). The dynamic development of gender variability. Journal of Homosexuality, 59(3), 398-421, doi:10.1080/00918369.2012.653310.2012.653303

Fydrich, T., Dowdall, D., \& Chambless, D. L. (1992). Reliability and validity of the Beck Anxiety Inventory. Journal of Anxiety Disorders, 6, 55-61. doi:10.1016/0887-6185(92)90026-4

Hill, D. B., Menvielle, E., Sica, K. M., \& Johnson, A. (2010). An affirmative intervention for families with gender variant children: Parental ratings of child mental health and gender. Journal of Sexual and Marital Therapy, 36(1), 6-23,doi:10.1080/00926230903375560

Kaye, L. W. (1996). Assessing the efficacy of a self-help support group program for older women. Journal of Women \& Aging, 7(4), 11-30, doi:10.1300/J074v07n04_03

Kohut, H. (1984). How does analysis cure? New York, N.Y.: International Universities Press.

Lee, R. M., \& Robbins, S. B. (1998). The relationship between social connectedness and anxiety, self-esteem, and social identity. Journal of Counseling Psychology, 45, 338-345.

Levitt, H. M., \& Ippolito, M. R. (2014). Being transgender: The experience of transgender identity development. Journal of Homosexuality, 61(12), 1727-1758. doi: 10.1080/ 00918369.2014.951262

Mathy, R. M. (2002). Transgender identity and suicidality in a nonclinical sample: Sexual orientation, psychiatric history, and compulsive behaviors. Journal of Psychology \& Human Sexuality, 14(4), 47.

Meier, P., Motmans, J., Ponnet, K., \& T’Sjoen, G. (2012). Female and male transgender quality of life: Socioeconomic and medical differences. The Journal of sexual medicine, 9(3), 743-750. doi: 10.1111/j.1743-6109.2011.02569

Menvielle, E. (2012). A comprehensive program for children with gender variant behaviors and gender identity disorders. Journal of Homosexuality, 59(3), 357-368, doi:10.1080/ 00918369.2012.653305

Meyer, M. D. E. (2004). "We're too afraid of these imaginary tensions”: Student organizing in lesbian, gay, bisexual, and transgender campus communities. Communication Studies, 55(4), 499-514.

Mitchell, K. J., Ybarra, M. L., \& Korchmaros, J. D. (2014). Sexual harassment among adolescents of different sexual orientations and gender identities. Child Abuse \& Neglect, 38(2), 280.

Minter, S. P. (2012). Supporting transgender children: New legal, social, and medical approaches. Journal of Homosexuality, 59(3), 422-433, doi:10.1080/00918369. 2012.653311

Phelps, K. W., Hodgson, J., Lamson, A. L., Swanson, M. S., \& White, M. B. (2012). Satisfaction with life and psychosocial factors among underserved minorities with type 2 diabetes. Social Indicators Research, 106(2), 359-370. doi:10.1007/s11205-011-9811-z

Pitts, M., Couch, M., Mulcare, H., Croy, S., \& Mitchell, A. (2009). Transgender people in Australia and New Zealand: Health, well-being and access to health services. Feminism \& Psychology, 19(4), 475-495.

Rogers, M. N. (2012). Enhancing LGBTQ emotional health: The role of LGBT community centers in addressing access to mental health and social support services (Doctoral dissertation, University of California Santa Barbara). Retrieved from http://search.proquest.com

Rothblum, E. D. (2013). Lesbian, gay, bisexual, and transgender communities. Handbook of psychology and sexual orientation (pp. 297-308). New York, NY: Oxford University Press.

Ryan, C., Russell, S. T., Huebner, D., \& Diaz, R. (2010). Family acceptance in adolescence and the health of LGBT young adults. Journal of Child and Adolescent Psychiatric Nursing, 23(4), 205.

San Francisco Dep. Of Public Health Study. (1999). The transgender community health project. Retrieved from http://hivinsite.ucsf.edu/InSite

Sánchez, F. J., \& Vilain, E. (2009). Collective self-esteem as a coping resource for male-to-female transsexuals. Journal of Counseling Psychology, 56(1), 202.

Singh, A. A., \& Burnes, T. R. (2009). Creating developmentally appropriate, safe counseling environments for transgender youth: The critical role of school counselors. Journal of LGBT Issues in Counseling, 3(3-4), 215-234.

Stein, E. (2012). Commentary on the treatment of gender variant and gender dysphoric children and adolescents: Common themes and ethical reflections. Journal of Homosexuality, 59(3), 480-500. doi: 10.1080/00918369.2012.653316

Verkuyten, M. (2008). Life satisfaction among ethnic minorities: The role of discrimination and group identification. Social Indicators Research, 89, 391-404, doi:10.1007/s11205- 008-9239-2 
Vries, A. L. C., \& Cohen-Kettenis, P. T. (2012). Clinical management of gender dysphoria in children and adolescents: The Dutch approach. Journal of Homosexuality, 59(3), 301- 320, doi:10.1080/00918369.2012.653300

Wyman, P. A., Sandler, I. N., Wolchik, S., \& Nelson, K. (2000). Resilience as cumulative competence promotion and stress protection: Theory and intervention. In R. P. Weissberg (Ed.), The promotion of wellness in children and adolescents (pp. 133-184). Washington, DC: CWLA Press.

Zucker, K. J., Wood, H., Singh, D., \& Bradley, S. J. (2012). A developmental, bio-psycho-social model for the treatment of children with gender identity disorder. Journal of Homosexuality, 59(3), 369-397, doi:10.1080/00918369.2012.653309 